\title{
A PRECURSOR TO THE RELATIONAL EVALUATION PROCEDURE: ANALYZING STIMULUS EQUIVALENCE II
}

\author{
VERONICA A. CULLINAN \\ University College Cork
}

\author{
DERMOT BARNES-HOLMES \\ National University of Ireland, Maynooth
}

\author{
PAUL M. SMEETS \\ Leiden University
}

\begin{abstract}
A series of experiments examined the precursor to the relational evaluation procedure (pREP). The pREP is capable of facilitating derived relational responding, but it is less effective than matching-to-sample (MTS) in producing equivalence class formation. Part 1 of the present study tested possible reasons for the inferiority of the pREP relative to MTS. The first two experiments compared the performances of subjects on two modified versions of the pREP with their performances on a simultaneous MTS procedure. The modifications did not improve performances on the pREP. Experiment 3 compared the pREP with a delayed MTS procedure but again MTS was more effective than the pREP in producing equivalence. Part 2 of the study determined whether PREP equivalence responding could be facilitated by preexposing subjects to a history of MTS training and testing. In Experiment 4, subjects were trained and tested on a MTS procedure until they reliably produced both symmetry and equivalence, and were then exposed to pREP training and testing using the same stimuli, and relations among stimuli, as employed for the MTS procedure. Following this, subjects were exposed to pREP training and testing using novel stimuli. All subjects reliably produced both symmetry and equivalence responding on the pREP with both familiar and novel stimuli. Experiment 5 determined whether using the same stimulus sets across the two procedures was necessary. Results showed that if symmetry and equivalence were shown on a MTS procedure followed immediately by pREP training and testing using novel stimuli, only 2 out of 4 subjects successfully demonstrated both symmetry and equivalence using the latter procedure.
\end{abstract}

This research was conducted as part of Veronica Cullinan's doctoral research program under the supervision of Dermot Barnes-Holmes. The authors thank Bill Mcllvane and an anonymous reviewer for their helpful and constructive comments on an earlier version of the current work. Requests for reprints may be addressed to Dermot Barnes-Holmes, Department of Psychology, National University of Ireland, Maynooth, Maynooth, Co. Kildare, Ireland (E-mail: Dermot.Barnes-Holmes@may.ie). 
In a typical stimulus equivalence experiment a matching-to-sample (MTS) procedure is used to establish a number of related conditional discriminations. For example, in a training task a single sample stimulus is presented along with two comparison stimuli, and a subject is required to choose one of the comparisons (alphanumeric labels are often used to designate these stimuli). During training, choosing comparison stimulus B1 when stimulus $A 1$ is presented as a sample produces positive feedback (e.g., the word "Correct"). Choosing stimulus B2, however, produces negative feedback (e.g., the word "Wrong"). In this way, the following four MTS performances may be established: $A 1 \rightarrow B 1, A 2 \rightarrow B 2$, $\mathrm{B} 1 \rightarrow \mathrm{C} 1, \mathrm{~B} 2 \rightarrow \mathrm{C} 2$. Once a subject has reached a predetermined training criterion (e.g., $90 \%$ correct responding in a block of training trials) he or she is presented with an equivalence test. During testing (without feedback) the subject may demonstrate a number of untrained matching performances, such as symmetry and combined symmetry and transitivity (equivalence). Symmetry requires that the conditional discriminations are functionally reversible (i.e., $B 1 \rightarrow A 1, B 2 \rightarrow A 2, C 1 \rightarrow B 1$, $C 2 \rightarrow B 2$ ), and combined symmetry and transitivity requires that the $A \rightarrow B$ and $B \rightarrow C$ conditional discriminations produce $C \rightarrow A$ responding (i.e., $\mathrm{C} 1 \rightarrow \mathrm{A} 1$, and $\mathrm{C} 2 \rightarrow \mathrm{A} 2$ ). When these untrained matching performances emerge they are often described as equivalence responding (see Barnes, 1994; Barnes, Browne, Smeets, \& Roche, 1995;. Barnes \& Holmes, 1991; Barnes \& Keenan, 1993; Barnes-Holmes \& Barnes-Holmes, 2000; Barnes-Holmes, Keane, Barnes-Holmes, \& Smeets, 2000; Cullinan, Barnes, Hampson, \& Lyddy, 1994; Dymond \& Barnes, 1994; Fields, Adams, Newman, \& Verhave, 1992; Hayes \& Barnes-Holmes, in press; Sidman, 1990).

In an effort to extend the analysis of stimulus equivalence and to gain a better understanding of those variables that control this behavioral effect, researchers have recently begun to examine alternatives to the MTS procedure (e.g., Barnes, Smeets, \& Leader, 1996; Leader, Barnes, \& Smeets, 1996; Schenk, 1995; Smeets, Leader, \& Barnes, 1997; Smeets, Schenk, \& Barnes, 1994). One such alternative is the precursor to the Relational Evaluation Procedure (pREP) which was described in Cullinan, Barnes, and Smeets (1998). This procedure was developed as part of a broader research program concerned with expanding the range of available methodologies for analyzing human language and cognition within the framework of Relational Frame Theory (RFT) (see BarnesHolmes, Dymond, Roche, \& Grey, 1999; Barnes-Holmes, Hayes, Hegarty, \& Dymond, in press; Barnes-Holmes, Healy, \& Hayes, in press; Hayes \& Barnes, 1997; Hayes \& Barnes-Holmes, in press). Each trial in the pREP consists of the presentation of one sample stimulus followed by either a positive or a negative comparison stimulus. Subjects are trained to press the space bar of a computer keyboard (during a 5-second response interval) when, for example, A1 is followed by B1 (sample-positive comparison), and not to press the space bar when $\mathrm{A} 1$ is followed by $\mathrm{B} 2$ (sample-negative comparison). In this way, a series of conditional 
discriminations can be trained, with positive and negative samplecomparison relations presented on separate trials (see D'Amato \& Colombo, 1985). The pREP can also be used to test for the emergent relations of symmetry and equivalence.

The four experiments described in Cullinan et al. (1998) compared training and testing using the pREP, with training and testing using a standard MTS procedure. In Experiment 1, subjects were trained using the pREP, and they were then exposed to pREP testing until they passed a test $(80 \%$ correct responding) or demonstrated a stable incorrect performance (the same pattern of incorrect responding across two consecutive tests). This was followed by MTS testing (until pass or stable), and finally pREP testing again. In Experiment 2, subjects were also exposed to pREP training, but the order of presentation of tests was MTS - pREP - MTS. Experiments 3 and 4 both involved MTS training first, but in Experiment 3 the order of presentation of tests was pREP - MTS pREP, and in Experiment 4 it was MTS - pREP - MTS. Over the four experiments it was found that 10 of the 20 subjects demonstrated equivalence responding on pREP tests, and 16 of the 20 subjects demonstrated equivalence responding on MTS tests.

Furthermore, although $50 \%$ of subjects demonstrated equivalence responding on a pREP test, a more detailed analysis revealed that the majority of these subjects had previously been exposed to MTS training and/or testing procedures. In fact, when subjects were exposed to pREP testing directly after pREP training (Experiment 1), only 1 of 5 subjects produced equivalence responding. A more general finding by Cullinan et al. (1998) was that the pREP readily produced symmetrical responding but was not very effective in producing equivalence responding. This would suggest that there may be some features of the pREP which, while readily facilitating symmetrical responding, do not facilitate equivalence responding. The current experiments were conducted to address a number of issues that arose out of the original study by Cullinan et al. (1998).

The present study will be presented in two parts. The first part (Experiments 1, 2, \& 3 ) involved making a number of modifications to the pREP, to determine whether a modified version of this procedure can produce equivalence more successfully than the original version. The second part (Experiments 4 \& 5) examined the relationship between prior exposure to MTS training and testing procedures and subsequent pREP performance, to establish the necessary conditions under which the pREP can reliably produce equivalence responding.

\section{General Method}

\section{Subjects}

Twenty students, 15 female and 5 male, attending University College Cork, participated in the experiments. Their ages ranged from 18 to 30 years, and they had no prior experience with stimulus equivalence research. They were recruited through notice-board advertisements and 
personal contacts, and they were randomly assigned to one of the five experiments (i.e., 4 subjects in each experiment).

\section{Apparatus and Setting}

All subjects were trained and tested individually in a quiet room free of distractions. The stimuli used were nonsense syllables (e.g., ZID, JOM, ROG, CUG, BEH, DAX) which will be represented here by the alphanumerics A1, B1, C1, A2, B2, C2. Stimuli were presented on an Apple Macintosh LC III computer, and subjects responded by pressing various marked keys on the keyboard. The computer was programmed in BBC BASIC to control the presentation of stimuli and record responses. Training and testing trials were presented in blocks, and after each block of trials subjects were free to move around or take a break, if they wished, while the experimenter checked the results. Sessions ranged from $\mathbf{3 0 ~ m i n}$ to $3 \mathrm{hr}$, and almost all subjects required more than one session.

\section{General Procedure}

General experimental design. All five experiments involved training subjects in a series of conditional discriminations, using either the pREP or a MTS procedure. When a subject reached the training criterion, he or she was tested for the emergence of symmetry and equivalence responding, with both trial types (i.e., symmetry and equivalence) mixed in each block of test trials (as in Cullinan et al., 1998). All subjects were presented with blocks of both MTS tests and pREP tests. Baseline conditional discriminations were retrained (to criterion) before each test in all five experiments. The order of presentation of the training and testing procedures will be described separately for each experiment.

Training, test, and stability criteria. The pREP training was presented in blocks of 40 trials, each consisting of 8 tasks (e.g., A1 $\rightarrow B 1 /$ press, $A 1 \rightarrow B 2 / n o$ Press) presented five times in a quasi-random order. Matching-to-sample and delayed matching-to-sample (DMTS) training trials were also presented in blocks of 40 trials, each consisting of 4 tasks (e.g., A1-B1/B2; A2-B1/B2) presented 10 times in quasi-random order, and the position of comparison stimuli counterbalanced across trials. The training criterion for both procedures was $90 \%$ correct (i.e., 36 trials correct out of 40 in any one block of training trials). Once this criterion was met, subjects were presented with a test phase. However, if time constraints prevented a subject being exposed to the test in the same session, he or she was retrained to criterion at the beginning of the next session.

The pREP test trials were presented in blocks of 120 trials, each consisting of 12 tasks (e.g., B1 $\rightarrow$ A1/press, B1 $\rightarrow A 2 /$ no press [symmetry]; $\mathrm{C} 1 \rightarrow \mathrm{A} 1 /$ press, $\mathrm{C} 1 \rightarrow \mathrm{A} 2 /$ no press [equivalence]) presented 10 times in a quasi-random order in each test block. The MTS and DMTS test trials were presented in blocks of 60 trials, each consisting of 6 tasks (e.g., $\mathrm{B} 1 \rightarrow \mathrm{A} 1 / \mathrm{A} 2$ [symmetry], $\mathrm{C} 1 \rightarrow \mathrm{A} 1 / \mathrm{A} 2$ [equivalence]) presented 10 times in a quasi-random order, again with the position of comparisons 
counterbalanced across trials. The criterion for passing a test using either procedure was 8 out of 10 correct responses on each testing task, in any one block of test trials. This criterion amounts to a total of $80 \%$ or more correct (see Cullinan et al., 1998, for an explanation for using an $80 \%$ criterion rather than $90 \%$ ). If a subject did not reach this test criterion he or she was retrained to criterion and then presented with the same test again. This continued until the subject either passed the test or demonstrated a stable incorrect performance on two consecutive test presentations (i.e., the difference between scores on each individual test task, across 2 blocks of test trials, was no more than 2 out of 10).

Programmed consequences. In all training procedures positive feedback consisted of an auditory tone, and "GOOD: POINTS = XX" appearing on the screen, displaying a total of points earned during that training block, incremented by one. Negative feedback consisted of an auditory tone and "BAD: POINTS = XX" appearing on the screen, displaying a total of points earned during that training block decremented by one. That is, a subject was awarded one point for each "correct" response and one point was deducted for each "incorrect" response. During testing phases there were no programmed consequences.

\section{PART 1: EXPERIMENTS 1, 2, AND 3}

One possible explanation for the poor performance of subjects on the pREP equivalence tests suggested by Cullinan et al. (1998) is that the 5$s$ response interval employed in their study may not have been sufficient in some cases to allow a subject to make a response (see Dube \& Mcllvane, 1996). Interestingly, when the data for subjects who had failed to produce equivalence were examined, it was found that the most common pattern of responding on all equivalence trials was "no press." Perhaps, therefore, subjects were simply failing to press because of lack of time. Although Cullinan et al. argued that the time factor may not provide a complete explanation for the lack of equivalence responding, it would nevertheless be wise to control for it in a future study.

The modified pREP used in the first experiment reported here allowed the subject to control the response interval, thus removing the suggested time-pressure involved in the experiments of Cullinan et al. This was done by introducing a response prompt in the form of a symbol which appeared on the screen after presentation of the sample and comparison. This prompt indicated to the subjects that they should now make a response (either press or not press the space bar). The computer then waited, indefinitely, until a response was emitted, and then the subjects were required to press a marked key on the keyboard to indicate that they had concluded their press or no press response.

Another possible weakness in the pREP used in our previous study relates to the possible ambiguity created when responses to all samplecomparison combinations are reinforced. For example, reinforcement is presented for pressing when presented with $\mathrm{A} 1$ and $\mathrm{B} 1$, and for not 
pressing when presented with $\mathrm{A} 1$ and $\mathrm{B} 2$. In this way, either press or no press responses can be predicted on the basis of baseline training. For example, if the test task presented was $\mathrm{C} 1 \rightarrow \mathrm{A} 1$ (equivalence), the training history of $\mathrm{A} 1 \rightarrow \mathrm{B} 1 \rightarrow$ press and $\mathrm{B} 1 \rightarrow \mathrm{C} 1 \rightarrow$ press would predict a response of press (via equivalence), but the training history of $A 1 \rightarrow B 2 \rightarrow$ no press and $\mathrm{B} 2 \rightarrow \mathrm{C} 1 \rightarrow$ no press would predict a response of no press (via equivalence). As Cullinan et al. (1998) pointed out, this problem relates only to transitivity/equivalence relations and does not affect symmetry tasks, and thus it could help to account for the "fracturing" of symmetry and equivalence on the pREP (see Dube \& Mcllvane, 1996, for a detailed discussion of this issue). The second experiment in the present study examined the foregoing issue. Specifically, it modified the original pREP training program so that subjects only received feedback after a press response. In the case of a no press response, no feedback was provided and the next trial was presented after the appropriate intertrial interval.

Another concern arising from the Cullinan et al. (1998) study is that the MTS procedure involved the simultaneous presentation of stimuli, whereas the pREP involved successive presentations of stimuli. Perhaps this difference played some role in the different results obtained across the two procedures. The third experiment in the current study addressed this issue by replicating one of the Cullinan et al. (1998) experiments using a DMTS procedure (i.e., samples and comparisons were not seen together).

\section{Experiment 1}

\section{Procedure}

Four subjects were trained to criterion using the first modified pREP (i.e., subject controlled response interval). They were trained to press the space bar when presented with positive stimulus pairs (e.g., $A 1 \rightarrow B 1 /$ press $\rightarrow$ good; $A 1 \rightarrow B 1 /$ no press $\rightarrow$ bad), and not to press the space bar when presented with negative stimulus pairs (e.g., A1 $\rightarrow B 2 /$ press-bad, $A 2 \rightarrow B 1 /$ no press $\rightarrow$ good) (see Figure 1, upper panel). When subjects had reached the training criterion, they were presented with the pREP test, which consisted of 8 symmetry tasks and 4 equivalence tasks. The reader is referred to Figure 1 (lower panel) for a schematic representation of each of the test tasks, and the predicted responses based on symmetry and equivalence relations (e.g., $B 1 \rightarrow A 1 /$ press; $B 1 \rightarrow A 2 /$ no press). If subjects did not reach the test criterion of 8 out of 10 correct responses on each test task, they were retrained using the pREP and then reexposed to the pREP test. This retraining and retesting continued until subjects either reached the test criterion or demonstrated a stable, incorrect performance (as defined in the General Procedure). Subjects were then retrained again using the pREP and were presented with a MTS test. This tested for the same relations as the pREP test, but on each trial two comparisons were presented with each sample (e.g., in a symmetry trial B1 might be presented as a sample with A1 and A2 as 


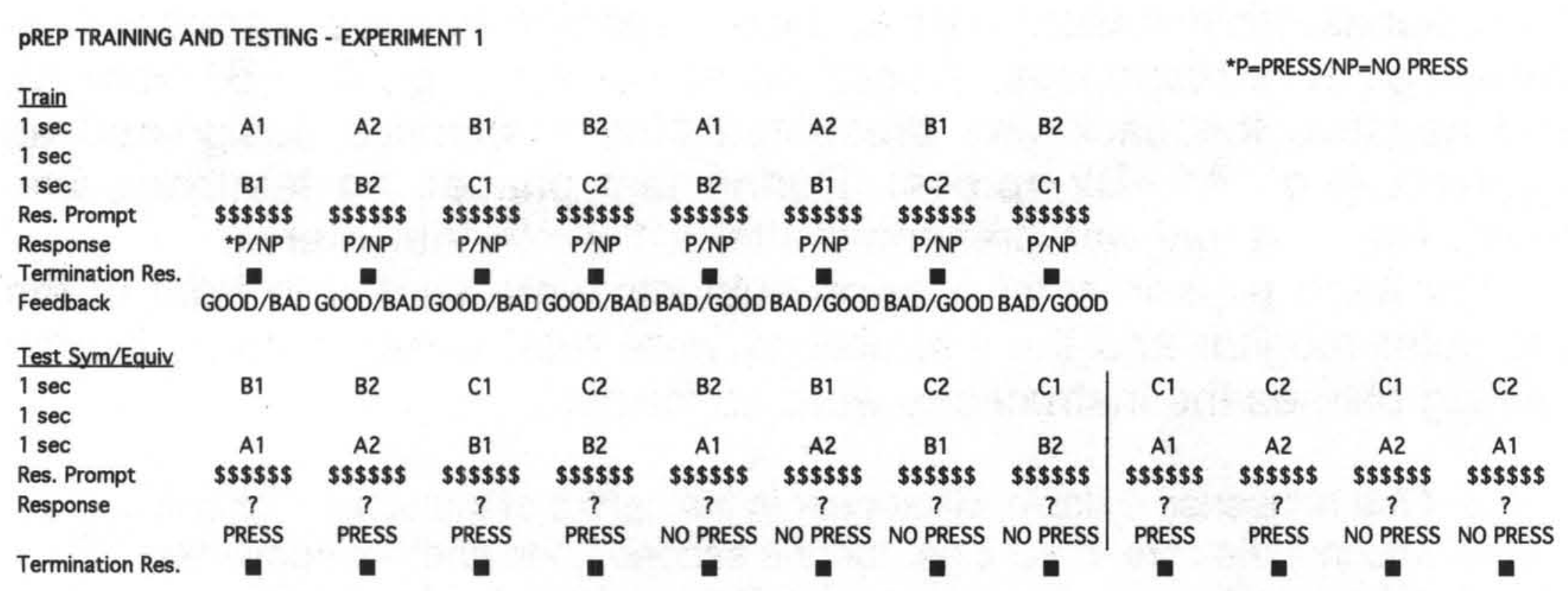

Figure 1. Schematic representation of pREP training and testing tasks used in Experiment 1. The notation P/NP followed by Good/Bad indicates that Pressing produced the Good feedback, whereas No Pressing produced the Bad feedback; where P/NP is followed by Bad/Good then Pressing produced the Bad feedback and No Pressing produced the Good feedback.

comparisons). Therefore, the MTS test consisted of 4 symmetry tasks and 2 equivalence tasks (see Figure 2, lower panel, for a schematic representation of these tasks). If subjects did not reach the test criterion on this MTS test they were again retrained (using the pREP) and retested until they either reached the test criterion or demonstrated a stable incorrect performance. Finally, subjects were retrained to criterion and tested using the pREP.

MTS TRAINING EXPERIMENTS 4 \& 5

\begin{tabular}{|c|c|c|c|c|c|c|c|}
\hline \multicolumn{2}{|c|}{ A1 } & \multicolumn{2}{|c|}{ A2 } & \multicolumn{2}{|c|}{ B1 } & \multicolumn{2}{|c|}{ B2 } \\
\hline 1 & & & & 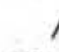 & & & 1 \\
\hline B1 & B2 & B1 & B2 & $\mathrm{Cl}$ & C2 & C1 & $\mathrm{C} 2$ \\
\hline
\end{tabular}

MTS TESTING (simultaneous MTS in Ex. 1, 2, 4 \& 5, DMTS in Ex. 3)

Test Sym/Equiv

\begin{tabular}{|c|c|c|c|c|c|c|c|c|c|c|c|}
\hline \multicolumn{2}{|c|}{ B1 } & \multicolumn{2}{|c|}{ B2 } & \multicolumn{2}{|c|}{ C1 } & \multicolumn{2}{|c|}{ C2 } & \multicolumn{2}{|c|}{ C1 } & \multicolumn{2}{|c|}{ C2 } \\
\hline ?/ & & & $?$ & ?/ & & & ? & ?/ & & & $\backslash ?$ \\
\hline $\mathrm{A} 1$ & A2 & A1 & A2 & B1 & B2 & B1 & B2 & A1 & A2 & A1 & A2 \\
\hline
\end{tabular}

Figure 2. Schematic representation of MTS training and testing tasks. On training tasks the lines between stimuli represent the relations for which positive feedback was provided. On test tasks (no feedback) the lines and question marks represent the responses predicted based on relations of symmetry and equivalence.

Precursor to the relational evaluation procedure: Modifying the response interval. In both training and testing phases a sample stimulus appeared in the center of the screen for $1 \mathrm{~s}$, the screen then cleared for $1 \mathrm{~s}$, and either a positive or negative comparison stimulus was presented for $1 \mathrm{~s}$. Then a response prompt $(\$ \$ \$ \$ \$)$ was presented. A subject made a response by either pressing the space bar or not pressing the space bar, and then pressing a response termination key (the number 6 key marked with a black square). During training phases, feedback (see programmed consequences) was presented on the screen for $1 \mathrm{~s}$ after 
the response termination key had been pressed. Positive feedback was presented after responses designated as correct (e.g., A1 $\rightarrow B 1 \rightarrow$ press), and negative feedback was presented after responses designated as incorrect (e.g,. A1 $\rightarrow$ B2 $\rightarrow$ press). During test phases no feedback was given. The next trial was presented after a 1-s intertrial interval.

For each experimental session subjects were seated in front of the computer monitor and the instructions were read aloud to them. During training phases the instructions were as follows:

One nonsense syllable will appear in the centre of the screen for one second, the screen will clear for one second, then another nonsense syllable will appear for one second. Then a symbol will appear on the screen. This symbol is a prompt asking you to make a response now. To make a response I want you to either press the space bar, or not press the space bar. When you have made your response, I want you to press this marked key on the keyboard [the number 6 key]. A message will then appear on the screen saying either "GOOD" and adding a point on to a running total which you will see on the screen, or "BAD" and subtracting a point from the running total. Then two more nonsense syllables will appear and the whole sequence will be repeated a number of times. When the experiment is finished you will be paid a penny for each point you earn, so you should try to earn as many points as possible. When this session is finished a message will appear asking you to call the experimenter. I will be waiting outside. Do you have any questions?

During testing phases similar instructions were presented except that subjects were informed that no feedback would be presented, and they were asked to "just do whatever you think is right."

Any questions asked were answered by repeating the relevant section of the instructions.

Matching-to-sample test. On MTS test trials a sample stimulus was presented near the top of the screen, followed $1 \mathrm{~s}$ later by two comparison stimuli presented to the left and right of the sample along the lower edge of the screen. All three stimuli remained visible on the screen until the subject made a response. Subjects responded by pressing one of two marked keys on the keyboard (the letters ' $Z$ ' and ' $M$ '). No feedback was given, and the next trial was presented after a 1-s intertrial interval.

The instructions for the MTS test were as follows:

In this part of the experiment one nonsense syllable will appear at the top of the screen and two at the bottom of the screen. I want you to look at the nonsense syllable at the top and choose one of the ones at the bottom. To choose the one on the left press the marked key on the left, to choose the one on the right press the marked key on the right. You will not get a message saying good or bad, so just do whatever you think is right. Some more nonsense syllables will then appear and the whole sequence will be repeated a number of times. Do you have any questions? 
Any questions were answered by repeating the relevant section of the instructions.

\section{Results and Discussion}

Table 1 shows the individual subject data for the initial pREP training, the total number of tests to which each subject was exposed, and the results of the final exposure to each type of test (a detailed breakdown of each subject's performance is shown in Appendix A). For the purposes of communication, a subject who reached the test criterion will be referred to as having 'passed' that test. A stable incorrect performance will be referred to as a 'fail.'

\section{Table 1}

Initial Training Trials, Number of Exposures to Tests, and Results for Symmetry and Equivalence on Final Exposure to Each Type of Test

\begin{tabular}{|c|c|c|c|c|c|}
\hline \multicolumn{2}{|l|}{ Experiment 1} & \multicolumn{4}{|c|}{ Subjects } \\
\hline & & 1 & 2 & 3 & 4 \\
\hline pREP Train & Tr. Trials to Criterion & 600 & 320 & 160 & 320 \\
\hline pREP Test & $\begin{array}{l}\text { No. of Exposures to Test } \\
\text { Results of Final Exp. - Sym. } \\
\text { - Equiv. }\end{array}$ & $\begin{array}{l}11 \\
\text { FAIL } \\
\text { FAIL }\end{array}$ & $\begin{array}{l}6 \\
\text { FAIL } \\
\text { FAIL }\end{array}$ & $\begin{array}{c}4 \\
\text { FAIL } \\
\text { FAIL }\end{array}$ & $\begin{array}{l}3 \\
\text { FAIL } \\
\text { FAIL }\end{array}$ \\
\hline MTS Test & $\begin{array}{l}\text { No. of Exposures to Test } \\
\text { Results of Final Exp. - Sym. } \\
\text { - Equiv. }\end{array}$ & $\begin{array}{c}1 \\
\text { PASS } \\
\text { PASS }\end{array}$ & $\begin{array}{l}4 \\
\text { PASS } \\
\text { FAIL }\end{array}$ & $\begin{array}{l}2 \\
\text { PASS } \\
\text { FAIL }\end{array}$ & $\begin{array}{c}1 \\
\text { PASS } \\
\text { PASS }\end{array}$ \\
\hline pREP Test & $\begin{array}{l}\text { No. of Exposures to Test } \\
\text { Results of Final Exp. - Sym. } \\
\text { - Equiv. }\end{array}$ & $\begin{array}{l}1 \\
\text { FAIL } \\
\text { FAIL }\end{array}$ & $\begin{array}{l}1 \\
\text { FAlL } \\
\text { FAIL }\end{array}$ & $\begin{array}{l}1 \\
\text { FAlL } \\
\text { FAIL }\end{array}$ & $\begin{array}{l}1 \\
\text { FAIL } \\
\text { FAIL }\end{array}$ \\
\hline Experiment 2 & & \multicolumn{4}{|c|}{ Subjects } \\
\hline pREP Train & Tr. Trials to Criterion & $\begin{array}{c}1 \\
200\end{array}$ & $\begin{array}{c}2 \\
520\end{array}$ & $\begin{array}{c}3 \\
160\end{array}$ & $\begin{array}{c}4 \\
360\end{array}$ \\
\hline pREP Test & $\begin{array}{l}\text { No. of Exposures to Test } \\
\text { Results of Final Exp. - Sym. } \\
\text { - Equiv. }\end{array}$ & $\begin{array}{c}1 \\
\text { PASS } \\
\text { PASS }\end{array}$ & $\begin{array}{l}3 \\
\text { PASS } \\
\text { FAIL }\end{array}$ & $\begin{array}{l}2 \\
\text { PASS } \\
\text { FAIL }\end{array}$ & $\begin{array}{l}6 \\
\text { FAIL } \\
\text { FAIL }\end{array}$ \\
\hline MTS Test & $\begin{array}{l}\text { No. of Exposures to Test } \\
\text { Results of Final Exp. - Sym. } \\
\text { - Equiv. }\end{array}$ & $\begin{array}{l}1 \\
\text { PASS } \\
\text { PASS }\end{array}$ & $\begin{array}{l}2 \\
\text { PASS } \\
\text { FAIL }\end{array}$ & $\begin{array}{l}2 \\
\text { PASS } \\
\text { FAIL }\end{array}$ & $\begin{array}{l}2 \\
\text { PASS } \\
\text { FAIL }\end{array}$ \\
\hline pREP Test & $\begin{array}{l}\text { No. of Exposures to Test } \\
\text { Results of Final Exp. - Sym. } \\
\text { - Equiv. }\end{array}$ & $\begin{array}{c}1 \\
\text { PASS } \\
\text { PASS }\end{array}$ & $\begin{array}{l}1 \\
\text { PASS } \\
\text { FAIL }\end{array}$ & $\begin{array}{l}1 \\
\text { PASS } \\
\text { FAIL }\end{array}$ & $\begin{array}{l}1 \\
\text { FAIL } \\
\text { FAIL }\end{array}$ \\
\hline Experiment 3 & & \multicolumn{4}{|c|}{ Subjects } \\
\hline & & 1 & 2 & 3 & 4 \\
\hline pREP Train & Tr. Trials to Criterion & 240 & 240 & 240 & 40 \\
\hline pREP Test & $\begin{array}{l}\text { No. of Exposures to Test } \\
\text { Results of Final Exp. - Sym. } \\
\text { - Equiv. }\end{array}$ & $\begin{array}{l}4 \\
\text { PASS } \\
\text { FAIL }\end{array}$ & $\begin{array}{l}3 \\
\text { PASS } \\
\text { FAIL }\end{array}$ & $\begin{array}{l}3 \\
\text { PASS } \\
\text { FAIL }\end{array}$ & $\begin{array}{l}1 \\
\text { PASS } \\
\text { PASS }\end{array}$ \\
\hline DMTS Test & $\begin{array}{l}\text { No. of Exposures to Test } \\
\text { Results of Final Exp. - Sym. } \\
\text { - Equiv. }\end{array}$ & $\begin{array}{l}2 \\
\text { PASS } \\
\text { PASS }\end{array}$ & $\begin{array}{l}2 \\
\text { PASS } \\
\text { FAIL }\end{array}$ & $\begin{array}{l}1 \\
\text { PASS } \\
\text { PASS }\end{array}$ & $\begin{array}{l}1 \\
\text { PASS } \\
\text { PASS }\end{array}$ \\
\hline pREP Test & $\begin{array}{l}\text { No. of Exposures to Test } \\
\text { Results of Final Exp. - Sym. } \\
\text { - Equiv. }\end{array}$ & $\begin{array}{l}1 \\
\text { PASS } \\
\text { FAIL }\end{array}$ & $\begin{array}{l}1 \\
\text { PASS } \\
\text { FAIL }\end{array}$ & $\begin{array}{l}1 \\
\text { PASS } \\
\text { FAIL }\end{array}$ & $\begin{array}{c}1 \\
\text { PASS } \\
\text { PASS }\end{array}$ \\
\hline
\end{tabular}


The number of pREP training trials required to reach training criterion ranged from 160 (S3) to 600 (S1). None of the 4 subjects responded in accordance with the relations of symmetry or equivalence, even after 11 exposures (S1) to the pREP tests. When subjects were then presented with a MTS test all 4 subjects responded in accordance with symmetry relations, and 2 responded in accordance with equivalence relations. Both of the subjects who demonstrated equivalence responding (S1 and S4) did so on their first exposure to the MTS test. When they were reexposed to the pREP test, all 4 subjects again failed to respond in accordance with either symmetry or equivalence relations. In Appendix A, it can be seen that by far the most common pattern or responding on the pREP was to press on all test trials, in particular symmetry trials. In fact, all 4 subjects made a press response on virtually all symmetry trials, whereas responding on equivalence trials was more varied. Only Subject 2 made press responses on virtually all equivalence trials. Overall, the modified pREP used in this experiment was ineffective in producing either symmetry or equivalence responding.

The results of this experiment indicate that removing the 5-s response interval from the pREP employed by Cullinan et al. (1998) did not result in higher levels of equivalence responding. In fact, the results showed that none of the 4 subjects demonstrated either symmetry or equivalence responding on pREP tests. Moreover, subjects in this experiment consistently made press responses on all symmetry test trials but only on some of the equivalence test trials. At the present time, it remains unclear as to why the modified pREP used in Experiment 1 produced test performances so different from those obtained when a 5-s response interval was employed. It seems likely, however, that the presentation of the response prompt and/or the termination response required in the modified version may have had some impact here. Future studies could systematically examine how this occurred, or alternatively another version of the pREP could be designed that removed the prompt and termination response, and also did not include a 5-s response interval (see General Discussion). Perhaps such a version would produce equivalence responding more effectively.

\section{Experiment 2}

\section{Procedure}

The sequence of training and testing procedures in Experiment 2 was identical to that of Experiment 1, but the pREP itself was modified (see Figure 3). Specifically, the response prompt and termination response were eliminated from the trial sequence. That is, if the space bar was pressed, after a stimulus pair had been presented, then the trial terminated immediately, but if the space bar was not pressed then the trial did not terminate until a 5-s response interval had elapsed (this part of the trial was identical to that reported in Cullinan et al., 1998). During training phases, feedback was provided (see programmed consequences) only after press 


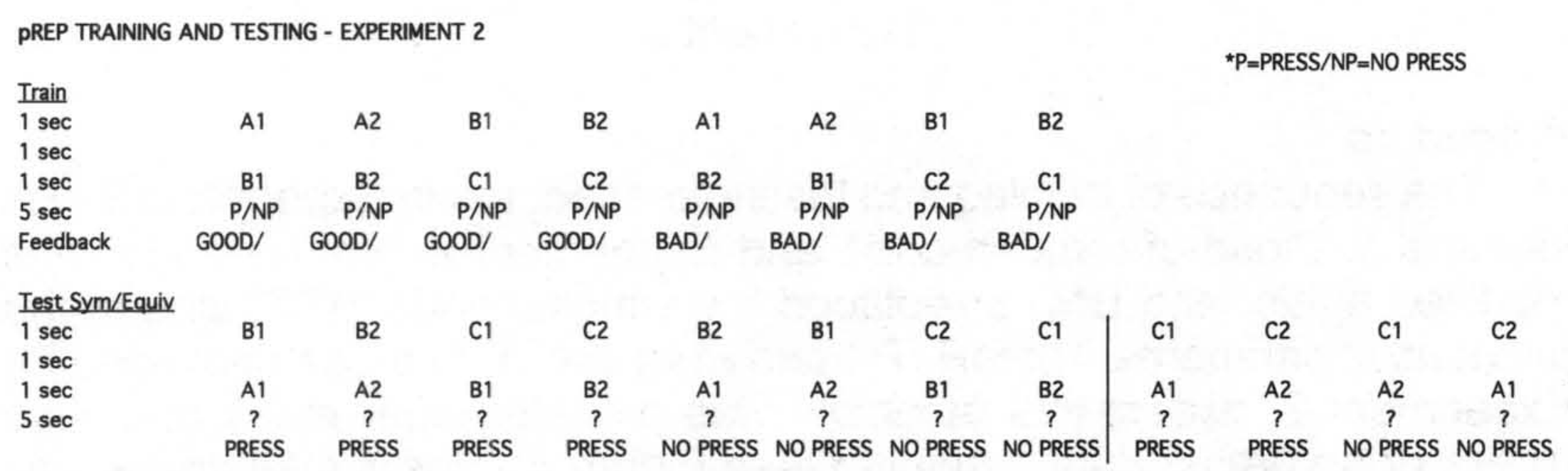

Figure 3. Schematic representation of pREP training and testing tasks used in Experiment 2. The notation P/NP followed by Good indicates that pressing produced the Good feedback, and no pressing produced no feedback message; when P/NP is followed by Bad, pressing produced the Bad feedback and no pressing produced no feedback message.

responses. Positive feedback was presented after press responses designated as correct (e.g., $\mathrm{A} 1 \rightarrow \mathrm{B} 1 \rightarrow$ press), negative feedback was presented after press responses designated as incorrect (e.g., $\mathrm{A} 1 \rightarrow \mathrm{B} 2 \rightarrow$ press). No feedback was provided after no press responses and the subject was not awarded any points. When a no press response occurred, the next trial was presented immediately after the 5-s response interval had elapsed. During test phases no feedback was given after any trials. The instructions were similar to those used in Experiment 1, with some minor modifications to accommodate the changes in the pREP trials (e.g., reference was made to the 5-s response interval; copies of the instructions are available from the authors).

\section{Results and Discussion}

Table 1 shows individual subject data for Experiment 2 (see Appendix B for a detailed breakdown). Subjects required between 160 (S3) and 520 (S2) training trials to reach the training criterion. Of the 4 subjects, 3 demonstrated symmetry responding on the pREP tests, but only 1 subject (S1) demonstrated equivalence responding. Subject 4 failed both symmetry and equivalence tests, and required 6 exposures to the test in order to demonstrate a stable incorrect performance. On the MTS tests all 4 subjects demonstrated symmetry responding, but only 1 of the 4 (S1) demonstrated equivalence responding. Reexposure to the pREP test resulted in 3 subjects again demonstrating symmetry but only 1 subject demonstrating equivalence.

Similar to Experiment 1, this modification to the pREP was not very effective in producing equivalence responding, but in contrast to Experiment 1 it was quite successful in producing symmetry. As can be seen in Table 1, one subject (S1) demonstrated both symmetry and equivalence on the first exposure to each type of test, and both S2 and S3 passed symmetry tests using both pREP and MTS procedures. This pattern of data is quite similar to that reported by Cullinan et al. (1998). The current data suggest, therefore, that reinforcing all sample-comparison pairs cannot be the only source of any ambiguity that might emerge among the equivalence relations that are generated using the pREP. 


\section{Experiment 3}

\section{Procedure}

The sequence of training and testing procedures in Experiment 3 was identical to those of Experiment 1 and Experiment 2, but the pREP was modified again, and DMTS replaced the simultaneous MTS used in the previous experiments. The pREP trials were similar to those described for Experiment 2, except that feedback was provided after every response (press or no press) during training (see Figure 4). Positive feedback was presented after all responses designated as correct (e.g.,

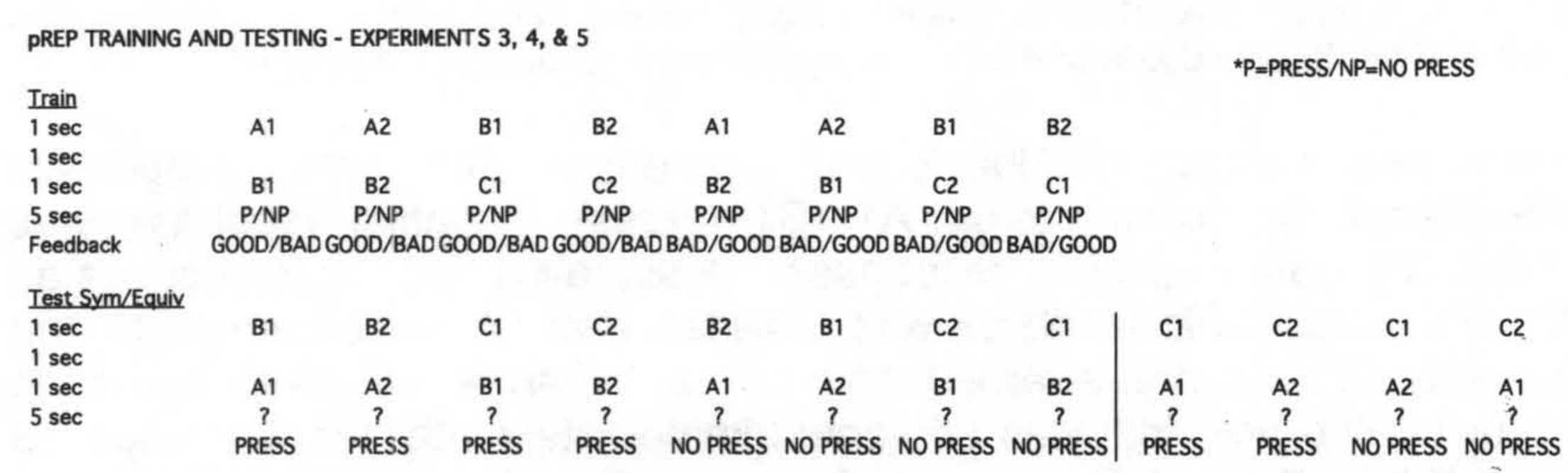

Figure 4. Schematic representation of pREP training and testing tasks used in Experiments 3 , 4, and 5. The notation P/NP followed by Good/Bad indicates that Pressing produced the Good feedback, whereas No Pressing produced the Bad feedback; where P/NP is followed by Bad/Good then Pressing produced the Bad feedback and No Pressing produced the good feedback.

$\mathrm{A} 1 \rightarrow \mathrm{B} 1 \rightarrow$ press; $\mathrm{A} 1 \rightarrow \mathrm{B} 2 \rightarrow$ no press). Negative feedback was presented after all responses designated as incorrect (e.g., $\mathrm{A} 1 \rightarrow \mathrm{B} 1 \rightarrow$ no press; $\mathrm{A} 1 \rightarrow \mathrm{B} 2 \rightarrow$ press). The DMTS procedure was identical to the simultaneous MTS procedure used in Experiments 1 and 2, except that after presentation of the sample stimulus the screen cleared for $1 \mathrm{~s}$ before presentation of the comparison stimuli (see Figure 4). The instructions were similar to those used in Experiment 2, with a minor modification to accommodate the change in feedback on the pREP and the use of DMTS (copies of these instructions are available from the authors).

\section{Results and Discussion}

Table 1 shows individual subject data for Experiment 3 (see Appendix C for a detailed breakdown). Subjects required between 40 (S4) and 240 (S1, S2, and S3) pREP training trials to reach criterion. All 4 subjects responded in accordance with symmetry relations on pREP tests, but only 1 subject (S4) responded in accordance with equivalence relations using the pREP. On the DMTS tests all 4 subjects responded in accordance with symmetry relations and 3 subjects responded in accordance with equivalence relations. On the final pREP tests all subjects again responded in accordance with symmetry relations and only 1 subject responded in accordance with equivalence relations. 
The results of the current experiment are very similar to those obtained from Experiment 3 reported by Cullinan et al. (1998), in which the same sequence of pREP training and testing, and matching-to-sample testing, was employed. The lack of any clear difference in the results obtained across the two experiments suggests that using a DMTS in the current experiment did not significantly affect the subjects' performances, relative to the MTS procedure employed in the previous study.

\section{PART 2: EXPERIMENTS 4 AND 5}

The results of the three previous experiments suggest that the modified versions of the pREP were less successful in producing equivalence and symmetry than the original procedure employed by Cullinan et al. (1998). Across the three experiments, only 2 out of 12 subjects demonstrated equivalence responding and only 7 showed symmetry using the pREP. In contrast, Cullinan et al. (1998) reported that 10 out of 20 subjects (across four experiments) demonstrated equivalence responding, and all 20 subjects demonstrated symmetry using the pREP.

At this point, one question that arises is whether the pREP could ever produce equivalence responding reliably across a number of subjects. Perhaps the ambiguous nature of the relations involved precludes such an outcome. Before drawing this conclusion, however, one area that deserves further attention is the role played by a history of MTS training and testing. In the original study by Cullinan et al. (1998), those subjects who did show equivalence with the pREP had such a history. Would it be possible to generate reliable equivalence responding with this procedure, if subjects had first been exposed to MTS training and testing? Experiments 4 and 5 addressed this question.

In Experiment 4, subjects were exposed to MTS training and testing until they demonstrated both symmetry and equivalence. They were then exposed to pREP training and testing using the same set of stimuli, and the same relations among stimuli, following which they were exposed to pREP training and testing using a novel stimulus set. It was expected that this complete overlap of stimulus sets across procedures would allow subjects to demonstrate equivalence using the pREP, first on the set of stimuli for which the relations had already been demonstrated using MTS, and subsequently on the novel set of stimuli. Experiment 5 examined whether this complete overlap of stimulus sets across procedures was required to demonstrate equivalence using the pREP.

\section{Experiment 4}

\section{Procedure}

Subjects were first exposed to MTS training (i.e., with programmed consequences for correct and incorrect responses) and testing (see 
Figure 2). They were trained to criterion and then repeatedly exposed to MTS tests, retraining, and retesting until they passed. Subsequently, they were trained to criterion and tested using the pREP (from Experiment 3 ) with the same stimuli and relations that were used in the MTS training and testing (Stimulus Set 1). For example, a MTS test task of the form C1$B 1 / B 2$ would be presented as two pREP tasks; $\mathrm{C} 1 \rightarrow \mathrm{B} 1 /$ press/no press and $\mathrm{C} 1 \rightarrow \mathrm{B} 2 /$ press/no press (correct responses are italicized). Subjects were repeatedly retrained and retested on the pREP until they passed or demonstrated a stable incorrect performance. They were then exposed to pREP training and testing using a novel set of stimuli, and again repeatedly retrained and retested until they passed or demonstrated a stable incorrect performance.

Instructions for both MTS training and testing were similar to those employed for MTS testing in Experiments 1 and 2 (i.e., the training instructions were modified to accommodate the use of feedback). Instructions for the pREP were the same as those used in Experiment 3.

\section{Results and Discussion}

Table 2 shows individual subject data for Experiment 4 (see Appendix D for a detailed breakdown). Subjects required between 40 (S4) and 120 (S1, S2, and S3) MTS training trials to reach criterion. All 4 subjects reliably demonstrated both symmetry and equivalence responding on their first, second, or third exposure to the MTS tests (using Set 1 stimuli). Following this performance, subjects required only 40 (S1, S2, and S4) to 80 (S3) pREP training trials to reach criterion using the same stimulus set, and all 4 reliably demonstrated both symmetry and equivalence responding on subsequent pREP tests using Stimulus Set 1. Having demonstrated this performance with Set 1 stimuli, these subjects then required 40 to 80 pREP training trials to reach criterion using a novel stimulus set (Set 2), and all 4 demonstrated both symmetry and equivalence on this novel set. Subjects 1,3 , and 4 demonstrated this performance on the first exposure to the test, and Subject 2 on the second exposure.

This experiment demonstrated that the pREP can indeed produce equivalence when subjects are provided with a history of responding in accordance with the same relations on a MTS procedure. Nevertheless, one question that arises from this finding relates to the fact that there was a complete overlap of stimulus sets and stimulus relations across procedures. In effect, subjects were allowed to demonstrate equivalence on a MTS procedure, then demonstrate the same performance on the pREP using the same stimuli and relations, before being trained and tested on the pREP using a novel set of stimuli. The final experiment in this series examined whether this complete overlap of stimuli and relations across procedures is necessary for the pREP to produce reliable symmetry and equivalence responding. 
Table 2

Number of Training Trials to Criterion, Number of Exposures to Tests, and Results for Symmetry and Equivalence on Final Exposure to Each Type of Test

\begin{tabular}{|c|c|c|c|c|c|}
\hline & \multicolumn{4}{|c|}{ Subjects } \\
\hline \multicolumn{2}{|l|}{ Experiment 4} & 1 & 2 & 3 & 4 \\
\hline MTS Train (SET 1 Stim.) & Tr. Trials to Criterion & 120 & 120 & 120 & 40 \\
\hline \multirow[t]{2}{*}{ MTS Test (SET 1 Stim.) } & No. of Exposures to Test & 1 & 2 & 3 & 2 \\
\hline & $\begin{array}{r}\text { Results of Final Exp. - Sym. } \\
\text { - Equiv. }\end{array}$ & $\begin{array}{l}\text { PASS } \\
\text { PASS }\end{array}$ & $\begin{array}{l}\text { PASS } \\
\text { PASS }\end{array}$ & $\begin{array}{l}\text { PASS } \\
\text { PASS }\end{array}$ & $\begin{array}{l}\text { PASS } \\
\text { PASS }\end{array}$ \\
\hline pREP Train (SET 1 Stim.) & Tr. Trials to Criterion & 40 & 40 & 80 & 40 \\
\hline pREP Test (SET 1 Stim.) & $\begin{array}{l}\text { No. of Exposures to Test } \\
\text { Results of Final Exp. - Sym. } \\
\text { - Equiv. }\end{array}$ & $\begin{array}{c}1 \\
\text { PASS } \\
\text { PASS }\end{array}$ & $\begin{array}{c}1 \\
\text { PASS } \\
\text { PASS }\end{array}$ & $\begin{array}{l}3 \\
\text { PASS } \\
\text { PASS }\end{array}$ & $\begin{array}{c}1 \\
\text { PASS } \\
\text { PASS }\end{array}$ \\
\hline \multirow{3}{*}{$\begin{array}{l}\text { pREP Train (SET } 2 \text { Stim.) } \\
\text { pREP Test (SET } 2 \text { Stim.) }\end{array}$} & Tr. Trials to Criterion & 40 & 80 & 80 & 40 \\
\hline & $\begin{array}{l}\text { No. of Exposures to Test } \\
\text { Results of Final Exp. - Sym. }\end{array}$ & $\begin{array}{c}1 \\
\text { PASS } \\
\text { DNCC }\end{array}$ & $\begin{array}{l}2 \\
\text { PASS }\end{array}$ & $\begin{array}{c}1 \\
\text { PASS }\end{array}$ & $\begin{array}{c}1 \\
\text { PASS } \\
\text { DACC }\end{array}$ \\
\hline & Equiv. & PASS & PASS & PASS & PASS \\
\hline \multirow{2}{*}{\multicolumn{2}{|c|}{ Experiment 5}} & & \multicolumn{2}{|c|}{ Subjects } & \\
\hline & & 1 & 2 & 3 & 4 \\
\hline MTS Train (SET 1 Stim.) & Tr. Trials to Criterion & 80 & 120 & 120 & 120 \\
\hline \multirow[t]{2}{*}{ MTS Test (SET 1 Stim.) } & No. of Exposures to Test & 1 & 4 & 1 & 1 \\
\hline & $\begin{array}{r}\text { Results of Final Exp. - Sym. } \\
\text { - Equiv. }\end{array}$ & $\begin{array}{l}\text { PASS } \\
\text { PASS }\end{array}$ & $\begin{array}{l}\text { PASS } \\
\text { PASS }\end{array}$ & $\begin{array}{l}\text { PASS } \\
\text { PASS }\end{array}$ & $\begin{array}{l}\text { PASS } \\
\text { PASS }\end{array}$ \\
\hline pREP Train (SET 2 Stim.) & Tr. Trials to Criterion & 80 & 200 & 280 & 200 \\
\hline \multirow[t]{2}{*}{ pREP Test (SET 2 Stim.) } & No. of Exposures to Test & 1 & 1 & 2 & 2 \\
\hline & $\begin{array}{r}\text { Results of Final Exp. - Sym. } \\
\text { - Equiv. }\end{array}$ & $\begin{array}{l}\text { PASS } \\
\text { PASS }\end{array}$ & $\begin{array}{l}\text { PASS } \\
\text { PASS }\end{array}$ & $\begin{array}{l}\text { PASS } \\
\text { FAlL }\end{array}$ & $\begin{array}{l}\text { PASS } \\
\text { FAIL }\end{array}$ \\
\hline \multicolumn{6}{|l|}{ Experiment 4 Procedure } \\
\hline MTS Train (SET 1 Stim.) & Tr. Trials to Criterion & & & 40 & 40 \\
\hline MTS Test (SET 1 Stim.) & $\begin{array}{l}\text { No. of Exposures to Test } \\
\text { Results of Final Exp. - Sym. } \\
\text { - Equiv. }\end{array}$ & & & $\begin{array}{c}1 \\
\text { PASS } \\
\text { PASS }\end{array}$ & $\begin{array}{c}1 \\
\text { PASS } \\
\text { PASS }\end{array}$ \\
\hline pREP Train (SET 1 Stim.) & Tr. Trials to Criterion & & & 40 & 40 \\
\hline \multirow[t]{2}{*}{ pREP Test (SET 1 Stim.) } & No. of Exposures to Test & & & 1 & 1 \\
\hline & $\begin{array}{l}\text { Results of Final Exp. - Sym. } \\
\text { - Equiv. }\end{array}$ & & & $\begin{array}{l}\text { PASS } \\
\text { PASS }\end{array}$ & $\begin{array}{l}\text { PASS } \\
\text { PASS }\end{array}$ \\
\hline pREP Train (SET 2 Stim.) & Tr. Trials to Criterion & & & 120 & 80 \\
\hline \multirow[t]{2}{*}{ pREP Test (SET 2 Stim.) } & No. of Exposures to Test & & & 1 & 1 \\
\hline & $\begin{array}{r}\text { Results of Final Exp. - Sym. } \\
\text { - Equiv. }\end{array}$ & & & $\begin{array}{l}\text { PASS } \\
\text { PASS }\end{array}$ & $\begin{array}{l}\text { PASS } \\
\text { PASS }\end{array}$ \\
\hline
\end{tabular}

\section{Experiment 5}

\section{Procedure}

The basic sequence of training and testing was similar to Experiment 4 , except that Stimulus Set 1 was used exclusively with MTS training and testing, and Stimulus Set 2 was used exclusively with pREP training and testing (i.e., no overlap of stimuli or relations). However, after completing MTS and pREP training and testing, the results were examined to determine whether any subjects had failed to pass the pREP. Any subject who did fail was subsequently exposed to the Experiment 4 design, which involved a complete overlap of stimulus sets and relations across 
procedures. Our objective was to determine whether this overlap would remediate the subjects' stable but incorrect performances. This involved retraining and retesting using the MTS procedure and Set 1 stimuli, followed by training and testing using the pREP with the same stimuli and relations (Set 1 ). This was then followed by retraining and retesting using the pREP with Set 2 stimuli. All instructions to subjects and programmed consequences were identical to those of Experiment 4.

\section{Results and Discussion}

Table 2 shows individual subject data for Experiment 5 (see Appendix E for a detailed breakdown). After either 80 (S1) or 120 (S2, S3, \& S4) training trials (using Stimulus Set 1), all 4 subjects demonstrated both symmetry and equivalence on the MTS procedure. When subjects were then presented with pREP training and novel stimuli (Stimulus Set 2) they required either 80 (S1), 200 (S2 \& S4) or 280 (S3) trials to reach the training criterion. Subjects 1 and 2 subsequently demonstrated both symmetry and equivalence on their first exposure to the pREP tests (Set 2). Subjects 3 and 4 passed symmetry, but they both demonstrated a stable incorrect performance on equivalence trials over two exposures to the pREP tests (Set 2). These 2 subjects ( $3 \& 4$ ) were then exposed to a complete overlap of stimulus sets (as in Experiment 4). They both reached the training criterion on the first block of 40 MTS trials and showed both symmetry and equivalence after one exposure to the MTS test (Set 1 stimuli). They both also reached the training criterion on the first block of 40 pREP training trials, and passed symmetry and equivalence on the first exposure to the pREP test (Set 1 stimuli). When they were then exposed to pREP training using Set 2 stimuli they required 120 (S3) or 80 (S4) trials to reach criterion, after which they both demonstrated symmetry and equivalence on their first exposures to the pREP test.

This experiment demonstrated that 2 of the 4 subjects transferred their equivalence performance from the MTS format to the pREP format. However, the other 2 subjects required the complete overlap of stimulus sets across the two procedures for equivalence responding to emerge. This suggests that although prior experience of demonstrating equivalence responding in a MTS format will facilitate its occurrence in pREP tests, a perhaps more powerful effect is achieved if there is a complete overlap of stimuli and relations across the two procedures.

\section{GENERAL DISCUSSION}

The modifications to the pREP examined in Part 1 of this study did not produce higher levels of equivalence responding than the original pREP reported in Cullinan et al. (1998). However, these data do indicate that a number of potentially important factors are not responsible, at least 
individually, for the weak equivalence-generating effect of the pREP. In Part 2 , it was shown that when subjects demonstrated equivalence responding on a MTS procedure, and were then presented with the same stimuli and relations on the pREP, equivalence responding emerged using the latter procedure. However, this method was maximally effective when there was a complete overlap of stimuli and relations across the two procedures.

One finding reported by Cullinan et al. (1998) was that the average number of training trials needed for subjects to reach criterion on the pREP was double the average needed to reach criterion on MTS. Cullinan et al. explained this by pointing to the fact that it requires twice the number of pREP training trials to establish each conditional discrimination as it does MTS trials. For example, the single MTS task $A 1 \rightarrow B 1 /$ not $B 2$ corresponds with the two pREP tasks $\mathrm{A} 1 \rightarrow \mathrm{B} 1 \rightarrow$ press, and $\mathrm{A} 1 \rightarrow \mathrm{B} 2 \rightarrow$ no press. Additional support for this interpretation is provided when the pREP training used in Experiment 3 of the present study (i.e., the same training employed by Cullinan et al., 1998) is compared with the MTS training used in Experiments 4 or 5 . The average number of training trials to reach criterion in Experiment 3 was 190 (pREP trials), and the averages were 100 and 110 (MTS trials) for Experiments 4 and 5, respectively. Interestingly, however, subjects exposed to the two modified versions of the pREP used in Experiments 1 and 2 required relatively large numbers of training trials before reaching the criterion. The average number of training trials required in Experiment 1 was 350 and in Experiment 2 was 310 . Contrary to expectation, therefore, the modifications applied to the pREP in these first two experiments appeared to hinder the extent to which this procedure may establish conditional discriminations in human adult subjects. Moreover, the deleterious effect of these modifications was also observed in the subjects' test performances. At the present time, it is not clear why the modified pREPs did not function as well as the original pREP during training or testing. Perhaps future research will address this issue.

There are two general issues that relate to all of the current experiments. First, the arbitrary assignment of nonsense syllables as experimental stimuli may have given rise to some instances of false positive equivalence responding. Perhaps, the 2 subjects who produced equivalence responding on the pREP in Part 1 of the study did so based on idiosyncratic nonarbitrary relations among the stimuli, rather than on derived arbitrary relations. Future researchers might consider this possibility. Second, the blocked presentation of test trials employed in the current study may have induced error patterns, such as responding press on all pREP test trials. Interpolating training and testing trials within test blocks could limit the potential for this type of error. Nevertheless, even if this modification improved pREP performance, the current source of the discrepancy between pREP and MTS (which also used a blocked presentation of test trials) would still remain unknown.

During the course of our studies using the pREP, we have come to suspect that the press/no press response requirement may be the source 
of some of the problems we have encountered with this procedure. Although we have no logical grounds on which to base this suspicion, in our future work we intend to provide a choice between pressing two different keys, rather than pressing or not pressing the space bar. Along with allowing subjects to control the duration of the response interval, this would allow for independent manipulation of the response options to investigate whether the nature of the response has a part to play in the outcome of the procedure. For example, in one study that we are about to commence (at the time of writing) the two response options will be the words, "Yes" and "No" in one condition, and the phrases "Goes With" and "Does Not Go With" in another condition. This strategy will allow us to introduce possibly important contextual cues for relational responding into the pREP. As outlined below, we believe that this approach may help us discover why the pREP so reliably fails to produce equivalence responding in human adults.

Although we have not yet clearly identified the key variables responsible for the inferiority of the pREP, we have demonstrated the utility of MTS procedures in facilitating the production of equivalence by the pREP. This would suggest that there are some features of the MTS procedure itself that serve as important contextual cues (at least for some subjects) for equivalence responding. At the present time, we suspect that the pREP often functions as a contextual cue for stimulus compounding, whereas MTS more readily functions as a cue for relational responding (see Wulfert, Dougher, \& Greenway, 1991, for a detailed description of, and evidence for, these two behavioral processes). More specifically, most adult subjects will likely have an educational history that has helped to establish the MTS task as discriminative for arbitrarily applicable sameness relations (see Barnes, 1994; Barnes \& Holmes, 1991; Barnes \& Roche, 1996), but with the pREP the presence of such a history seems less likely - children are not usually taught about sameness relations using go/no-go procedures. The foregoing interpretation would certainly account for the fact that the pREP so readily produces symmetry but not equivalence, in that the former may occur via stimulus compounding, but the latter does not (at least under normal circumstances) (see Wulfert et al., 1991). Indeed, there is certainly mounting evidence to suggest that symmetry and equivalence do not necessarily function as whole or complete behavioral units (Pilgrim \& Galizio, 1990,1995; Roche, Barnes, \& Smeets, 1997; but see Saunders, Drake, \& Spradlin, 1999). In any case, if we are correct in suggesting that MTS possesses relational cues not present in the pREP, the next step in our research program could involve searching systematically for these cues. If such cues are identified, they could be incorporated into the pREP to produce an effective successive discrimination (go/no-go) equivalence methodology. 


\section{References}

BARNES, D. (1994). Stimulus equivalence and relational frame theory. The Psychological Record, 44, 91-124.

BARNES, D., BROWNE, M., SMEETS, P. M., \& ROCHE, B. (1995). A transfer of functions and a conditional transfer of functions through equivalence relations in three- to six-year-old children. The Psychological Record, 45, 405-430.

BARNES, D., \& HOLMES, Y. (1991). Radical behaviorism, stimulus equivalence and human cognition. The Psychological Record, 41, 19-30.

BARNES, D., \& KEENAN, M. (1993). A transfer of functions through derived arbitrary and non-arbitrary stimulus relations. Journal of the Experimental Analysis of Behavior, 59, 61-81.

BARNES, D., \& ROCHE, B. (1996). Relational frame theory and stimulus equivalence are fundamentally different: A reply to Saunders' commentary. The Psychological Record, 46, 489-507.

BARNES, D., SMEETS, P. M., \& LEADER, G. (1996). Procedures for generating emergent matching performances: Implications for stimulus equivalence. In T. R. Zentall \& P. M. Smeets (Eds.), Stimulus class formation: Advances in psychology (pp. 153-171). Holland: Elsevier.

BARNES-HOLMES, D., \& BARNES-HOLMES, Y. (2000). Explaining complex behavior: Two perspectives on the concept of generalized operant classes. The Psychological Record, 50, 251-265.

BARNES-HOLMES, D., DYMOND, S., ROCHE, B., \& GREY, I. (1999). Behaviour analysis: A new agenda for language and cognition. The Psychologist, 12, 500-504.

BARNES-HOLMES, D., HAYES, S. C., HEGARTY, N., \& DYMOND, S. (in press). Multiple stimulus relations, the transformations of stimulus functions and the limits of the class concept. In S. C. Hayes \& D. Barnes-Holmes (Eds.), Relational frame theory: Creating an alternative behavioral agenda in language and cognition. Reno, NV: Context Press.

BARNES-HOLMES, D., HEALY, O., \& HAYES, S. C. (in press). Relational frame theory and the relational evaluation procedure: Approaching human language as derived relational responding. In J. C. Leslie \& D. E. Blackman (Eds.), Experimental and applied analyses of human behavior. Reno, NV: Context Press.

BARNES-HOLMES, D., KEANE, J., BARNES-HOLMES, Y., \& SMEETS, P. M. (2000). A derived transfer of emotive functions as a means of establishing differential preferences for soft drinks. The Psychological Record, 50, 493-511.

CULLINAN, V. A., BARNES, D., HAMPSON, P. J., \& LYDDY, F. (1994). A transfer of explicitly and nonexplicitly trained sequence responses through equivalence relations: An experimental demonstration and connectionist model. The Psychological Record, 44, 559-585.

CULLINAN, V. A., BARNES, D., \& SMEETS, P. M. (1998). A precursor to the relational evaluation procedure: Analyzing stimulus equivalence. The Psychological Record, 48, 121-145.

D'AMATO, M. R., \& COLOMBO, M. (1985). Auditory matching-to-sample in monkeys (Cebus apella). Animal Learning and Behavior, 13, 375-382.

DUBE, W. V., \& MCILVANE, W. J. (1996). Some implications of a stimulus control topography analysis for emergent behavior and stimulus classes. In T. R. Zentall \& P. M. Smeets (Eds.), Stimulus class formation in humans and animals: Advances in psychology. NL: Elsevier. 
DYMOND, S., \& BARNES, D. (1994). A transfer of self-discrimination response functions through equivalence relations. Journal of the Experimental Analysis of Behavior, 62, 251-267.

FIELDS, L., ADAMS, B. J., NEWMAN, S., \& VERHAVE, T. (1992). Interactions among emergent relations during equivalence class formation. The Quarterly Journal of Experimental Psychology, 45B, 125-138.

HAYES, S. C., \& BARNES, D., (1997). Analyzing derived stimulus relations requires more than the concept of stimulus class. Journal of the Experimental Analysis of Behavior, 68, 235-244.

HAYES, S. C., \& BARNES-HOLMES, D. (in press). Relational frame theory: Creating an alternative behavioral agenda in language and cognition. Reno, NV: Context Press.

LEADER, G., BARNES, D., \& SMEETS, P. M., (1996). Establishing equivalence relations using a respondent-type training procedure. The Psychological Record, 46, 685-706.

PILGRIM, C., \& GALIZIO, M. (1990). Relations between baseline contingencies and equivalence probe performances. Journal of the Experimental Analysis of Behavior, 54, 213-224.

PILGRIM, C., \& GALIZIO, M. (1995). Reversal of baseline relations and stimulus equivalence: I. Adults. Journal of the Experimental Analysis of Behavior, 63, 225-238.

ROCHE, B., BARNES, D.. \& SMEETS, P. M. (1997). Incogruous stimulus paring and conditional discrimination training: Effects on rational responding. Journal of the Experimental Analysis of Behavior, 68, 143-160.

SAUNDERS, R. R., DRAKE, K. M., \& SPRADLIN, J. E. (1999). Equivalence class establishment, expansion, and modification in preschool children. Journal of the Experimental Analysis of Behavior, 71, 195-214.

SCHENK, J. J. (1995). Complex stimuli in nonreinforced simple discrimination tasks: Emergent simple and conditional discriminations. The Psychological Record, 45, 477-494.

SIDMAN, M. (1990). Equivalence relations: Where do they come from? In D. E. Blackman \& H. Lejeune (Eds.), Behaviour analysis in theory and practice. U.K.: Lawrence Erlbaum.

SMEETS, P. M., LEADER, G., \& BARNES, D. (1997). Establishing stimulus classes with adults and children using a respondent training procedure: $A$ follow-up study. The Psychological Record, 47, 285-308.

SMEETS, P. M., SCHENK, J. J., \& BARNES, D. (1994). Establishing arbitrary stimulus classes via identity matching training and nonreinforced matching with complex stimuli. Quarterly Journal of Experimental Psychology, 48B, 311-328.

WULFERT, E., DOUGHER, M. J., \& GREENWAY, D. E. (1991). Protocol analysis of the correspondence of verbal behavior and equivalence class formation. Journal of the Experimental Analysis of Behavior, 56, 489-504. 


\section{APPENDIX A}

Detailed Results for Each Exposure to pREP Tests and MTS Tests in Experiment 1

Experiment 1

SYMMETRY EQUIVALENCE NON-SYMMETRY NON-EQUIV.

Test tasks

B1-A1 B2-A2 C1-B1 C2-B2 C1-A1 C2-A2 B1-A2 B2-A1 C1-B2 C2-B1 C1-A2 C2-A1

Required response No. Trials ${ }^{*} P \quad P \quad P \quad P \quad P \quad P$ "NP NP NP NP NP NP

\section{Subject 1}

pREP train to crit. $\quad 600$

pREP test

pREP retrain to crit. 80

pREP test

pREP retrain to crit. 40

pREP test

pREP retrain to crit. 80

pREP test

pREP retrain to crit. 40

pREP test

pREP retrain to crit. 80

pREP test

pREP retrain to crit. 80

pREP test

pREP retrain to crit. 40

pREP test

pREP retrain to crit. 40

pREP test

pREP retrain to crit. 40

pREP test

pREP retrain to crit. 40

pREP test

$\begin{array}{llllllllllll}7 & 2 & 7 & 7 & 5 & 3 & 4 & 9 & 6 & 10 & 5 & 10\end{array}$

$\begin{array}{llllllllllll}9 & 5 & 8 & 10 & 1 & 0 & 1 & 5 & 3 & 10 & 8 & 10\end{array}$

$\begin{array}{llllllllllll}10 & 9 & 9 & 9 & 0 & 1 & 2 & 2 & 1 & 9 & 10 & 10\end{array}$

$\begin{array}{llllllllllll}1 & 1 & 2 & 1 & 9 & 4 & 8 & 7 & 9 & 1 & 3 & 5\end{array}$

$\begin{array}{llllllllllll}1 & 0 & 10 & 9 & 1 & 0 & 8 & 10 & 0 & 8 & 9 & 9\end{array}$

$\begin{array}{llllllllllll}1 & 0 & 10 & 8 & 10 & 10 & 9 & 10 & 10 & 10 & 10 & 9\end{array}$

$\begin{array}{llllllllllll}0 & 0 & 9 & 9 & 9 & 1 & 10 & 10 & 10 & 10 & 8 & 8\end{array}$

$\begin{array}{llllllllllll}1 & 0 & 0 & 0 & 10 & 1 & 9 & 10 & 10 & 10 & 0 & 0\end{array}$

$\begin{array}{llllllllllll}9 & 7 & 9 & 9 & 9 & 1 & 10 & 10 & 10 & 10 & 3 & 9\end{array}$

$\begin{array}{llllllllllll}10 & 10 & 10 & 10 & 9 & 8 & 10 & 10 & 10 & 10 & 1 & 10\end{array}$

pREP retrain to crit. 40

MTS test

pREP test

$\begin{array}{llllllllllll}10 & 10 & 10 & 10 & 9 & 10 & 10 & 10 & 10 & 10 & 0 & 8\end{array}$

Subject 2

pREP train to crit. $\quad 320$

pREP test

pREP retrain to crit. 80

pREP test

pREP retrain to crit. 40

pREP test

pREP retrain to crit. 40

pREP test

pREP retrain to crit. 40

pREP test

pREP retrain to crit. 40

pREP test

$\begin{array}{llllllllllll}10 & 10 & 10 & 9 & 10 & 10 & 0 & 0 & 0 & 1 & 0 & 0\end{array}$

$\begin{array}{llllllllllll}10 & 10 & 10 & 10 & 10 & 0 & 10 & 10 & 10 & 10 & 10 & 0\end{array}$

pREP retrain to crit. 40

MTS test

pREP retrain to crit. 40

MTS test

pREP retrain to crit. 40

MTS test

pREP retrain to crit. 40

MTS test

$\begin{array}{llllllllllll}8 & 10 & 10 & 4 & 10 & 3 & 10 & 10 & 10 & 8 & 2 & 4\end{array}$

$\begin{array}{llllllllllll}10 & 9 & 8 & 8 & 8 & 0 & 8 & 8 & 10 & 9 & 0 & 8\end{array}$

$\begin{array}{llllllllllll}10 & 9 & 10 & 10 & 10 & 4 & 10 & 10 & 10 & 9 & 3 & 8\end{array}$

$\begin{array}{llllllllllll}9 & 10 & 10 & 10 & 10 & 0 & 9 & 10 & 10 & 10 & 10 & 10\end{array}$

$\begin{array}{llllllllllll}8 & 10 & 8 & 10 & 9 & 8 & 10 & 10 & 10 & 10 & 10 & 10\end{array}$

$\begin{array}{llllllllllll}10 & 10 & 10 & 10 & 10 & 10 & 10 & 10 & 10 & 10 & 10 & 10\end{array}$

pREP retrain to crit. 40

pREP test

$\begin{array}{llllllllllll}3 & 9 & 10 & 9 & 7 & 4 & 7 & 1 & 0 & 1 & 3 & 6\end{array}$

$\begin{array}{llllllllllll}5 & 5 & 7 & 5 & 5 & 5 & 5 & 5 & 3 & 5 & 4 & 5\end{array}$

$\begin{array}{llllllllllll}10 & 10 & 10 & 10 & 10 & 0 & 0 & 0 & 0 & 0 & 0 & 10\end{array}$

$\begin{array}{llllllllllll}10 & 10 & 10 & 10 & 10 & 0 & 0 & 0 & 0 & 0 & 0 & 10\end{array}$

$\begin{array}{llllllllllll}10 & 9 & 10 & 10 & 10 & 10 & 10 & 10 & 10 & 10 & 10 & 9\end{array}$ 
Subject 3

pREP train to crit. $\quad 160$

pREP test

pREP retrain to crit. 80

pREP test

pREP retrain to crit. 40

pREP test

pREP retrain to crit. 40

pREP test

$\begin{array}{llllllllllll}9 & 10 & 1 & 9 & 8 & 10 & 10 & 9 & 10 & 9 & 0 & 0\end{array}$

$\begin{array}{llllllllllll}8 & 10 & 10 & 10 & 10 & 10 & 10 & 10 & 10 & 10 & 0 & 2\end{array}$

$\begin{array}{llllllllllll}9 & 10 & 10 & 10 & 10 & 4 & 10 & 10 & 10 & 10 & 0 & 0\end{array}$

pREP retrain to crit. 40

MTS test

pREP retrain to crit. 40

MTS test

$\begin{array}{llllllllllll}10 & 10 & 10 & 10 & 10 & 3 & 10 & 10 & 10 & 10 & 2 & 2\end{array}$

$\begin{array}{llllllllllll}10 & 10 & 10 & 9 & 2 & 10 & 0 & 0 & 0 & 1 & 8 & 0\end{array}$

pREP retrain to crit. 40

pREP test

$\begin{array}{llllllllllll}10 & 10 & 10 & 9 & 0 & 10 & 0 & 0 & 0 & 1 & 10 & 0\end{array}$

$\begin{array}{llllllllllll}10 & 10 & 10 & 9 & 7 & 0 & 10 & 10 & 10 & 10 & 1 & 0\end{array}$

Subject 4

pREP train to crit. $\quad 320$

pREP test

pREP retrain to crit. 40

pREP test

pREP retrain to crit. 120

pREP test

pREP retrain to crit. 80

MTS test

pREP retrain to crit. 40

pREP test

$\begin{array}{llllllllllll}10 & 10 & 10 & 10 & 0 & 10 & 9 & 10 & 10 & 10 & 10 & 0\end{array}$

$\begin{array}{llllllllllll}10 & 10 & 9 & 10 & 0 & 10 & 9 & 10 & 10 & 9 & 10 & 0\end{array}$

$\begin{array}{llllllllllll}10 & 10 & 10 & 10 & 10 & 10 & 0 & 0 & 0 & 0 & 0 & 0\end{array}$

Note. ${ }^{*} \mathrm{P}=$ Press, $\mathrm{NP}=$ No Press

APPENDIX B

Detailed Reslts for Each Exposure to pREP Tests and MTS Tests in Experiment 2

Experiment 2

SYMMETRY EQUIVALENCE NON-SYMMETRY NON-EQUIV.

Test tasks

B1-A1 B2-A2 C1-B1 C2-B2 C1-A1 C2-A2 B1-A2 B2-A1 C1-B2 C2-B1 C1-A2 C2-A1

$\begin{array}{llllllllllllll}\text { Required response } & \text { No. trials } & { }^{*} P & P & P & P & P & P & & \end{array}$

Subject 1

pREP train to crit. $\quad 200$

pREP test

pREP retrain to crit. 80

MTS test

$\begin{array}{llllllllllll}9 & 10 & 10 & 10 & 10 & 10 & 0 & 0 & 0 & 0 & 0 & 0\end{array}$

pREP retrain to crit. 40

pREP test

$\begin{array}{llllllllllll}10 & 8 & 10 & 10 & 10 & 10 & 0 & 2 & 0 & 0 & 0 & 0\end{array}$

Subject 2

pREP train to crit. $\quad 520$

pREP test

pREP retrain to crit. 40

pREP test

pREP retrain to crit. 40

pREP test

$\begin{array}{llllllllllll}10 & 10 & 10 & 10 & 9 & 10 & 0 & 0 & 0 & 1 & 0 & 0\end{array}$

pREP retrain to crit. 40

MTS test

pREP retrain to crit. 40

MTS test

pREP retrain to crit. 40

pREP test

\begin{tabular}{llllllllllll}
10 & 10 & 10 & 10 & 0 & 2 & 1 & 0 & 3 & 0 & 5 & 0 \\
10 & 10 & 10 & 10 & 0 & 0 & 0 & 0 & 3 & 0 & 0 & 0 \\
10 & 10 & 10 & 10 & 0 & 0 & 0 & 0 & 1 & 0 & 0 & 0 \\
\hline
\end{tabular}

$\begin{array}{llllllllllll}10 & 10 & 10 & 10 & 0 & 0 & 0 & 0 & 0 & 0 & 0 & 0\end{array}$

$\begin{array}{llllllllllll}10 & 10 & 10 & 10 & 0 & 0 & 0 & 0 & 0 & 0 & 0 & 0\end{array}$

$\begin{array}{llllllllllll}10 & 9 & 10 & 10 & 0 & 0 & 0 & 0 & 0 & 0 & 0 & 0\end{array}$ 
Subject 3

pREP train to crit. $\quad 160$

pREP test

pREP retrain to crit. 40

pREP test

$\begin{array}{llllllllllll}10 & 8 & 10 & 10 & 1 & 1 & 0 & 0 & 2 & 1 & 2 & 9\end{array}$

pREP retrain to crit. 40

MTS test

pREP retrain to crit. 40

MTS test

$\begin{array}{llllllllllll}9 & 10 & 10 & 10 & 0 & 0 & 0 & 0 & 0 & 0 & 0 & 10\end{array}$

pREP retrain to crit. 40

pREP test

$\begin{array}{llllllllllll}10 & 10 & 10 & 10 & 10 & 0 & 0 & 0 & 0 & 0 & 0 & 10\end{array}$

$\begin{array}{llllllllllll}10 & 10 & 10 & 10 & 10 & 0 & 0 & 0 & 0 & 0 & 0 & 10\end{array}$

$\begin{array}{llllllllllll}10 & 10 & 10 & 10 & 10 & 0 & 0 & 0 & 0 & 0 & 0 & 10\end{array}$

Subject 4

pREP train to crit. $\quad 360$

pREP test

pREP retrain to crit. 80

pREP test

pREP retrain to crit. 40

pREP test

pREP retrain to crit. 80

pREP test

pREP retrain to crit. 40

pREP test

pREP retrain to crit. 40

pREP test

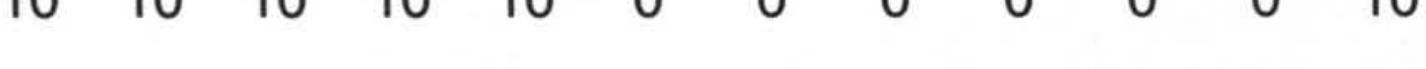

pREP retrain to crit. 40

MTS test

pREP retrain to crit. 40

MTS test

$\begin{array}{llllllllllll}10 & 10 & 10 & 10 & 0 & 0 & 0 & 0 & 0 & 0 & 0 & 0\end{array}$

$\begin{array}{llllllllllll}7 & 8 & 7 & 4 & 4 & 6 & 4 & 4 & 6 & 6 & 5 & 5\end{array}$

$\begin{array}{llllllllllll}0 & 2 & 1 & 9 & 10 & 2 & 10 & 10 & 9 & 10 & 10 & 10\end{array}$

pREP retrain to crit. 40

pREP test

Note. ${ }^{*} \mathrm{P}=$ Press, $\mathrm{NP}=$ No Press

$\begin{array}{llllllllllll}10 & 10 & 10 & 10 & 0 & 9 & 0 & 0 & 0 & 0 & 10 & 1\end{array}$

$\begin{array}{llllllllllll}9 & 10 & 10 & 10 & 0 & 10 & 1 & 0 & 0 & 0 & 10 & 0\end{array}$

$\begin{array}{llllllllllll}3 & 2 & 3 & 6 & 10 & 10 & 10 & 10 & 10 & 10 & 10 & 10\end{array}$

\section{APPENDIX C}

Detailed Results for Each Exposure to pREP Tests and DMTS Test in Experiment 3

Experiment 3

SYMMETRY

Test tasks

Required response

Subject 1

pREP train to crit. 240

pREP test

pREP retrain to crit. 40

pREP test

pREP retrain to crit. 40

pREP test

pREP retrain to crit. 40

pREP test

SYMMETRY EQUIVALENCE NON-SYMMETRY NON-EQUIV. B1-A1 B2-A2 C1-B1 C2-B2 C1-A1 C2-A2 B1-A2 B2-A1 C1-B2 C2-B1C1-A2 C2-A1

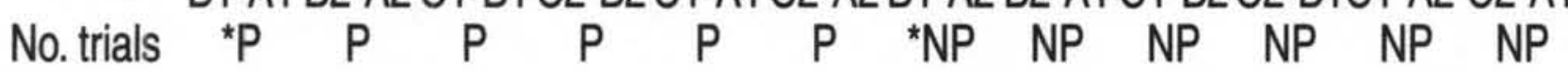

$\begin{array}{llllllllllll}0 & 0 & 3 & 0 & 2 & 1 & 0 & 0 & 7 & 2 & 0 & 9\end{array}$

$\begin{array}{llllllllllll}1 & 2 & 1 & 1 & 0 & 0 & 0 & 0 & 0 & 0 & 0 & 0\end{array}$

$\begin{array}{llllllllllll}9 & 10 & 10 & 10 & 0 & 0 & 0 & 0 & 0 & 0 & 0 & 0\end{array}$

$\begin{array}{llllllllllll}10 & 10 & 10 & 10 & 0 & 0 & 0 & 0 & 0 & 0 & 0 & 0\end{array}$

pREP retrain to crit. 40

DMTS test

pREP retrain to crit. 40

DMTS test

pREP retrain to crit. 40

pREP test

Subject 2

pREP train to crit. 240

pREP test

$\begin{array}{llllllllllll}7 & 10 & 8 & 10 & 8 & 8 & 3 & 0 & 2 & 0 & 2 & 2\end{array}$

$\begin{array}{llllllllllll}10 & 10 & 10 & 10 & 9 & 10 & 0 & 0 & 0 & 0 & 1 & 0\end{array}$

$\begin{array}{llllllllllll}10 & 10 & 10 & 10 & 0 & 0 & 0 & 0 & 0 & 0 & 0 & 0\end{array}$

$\begin{array}{llllllllllll}7 & 10 & 9 & 8 & 0 & 1 & 9 & 1 & 0 & 0 & 0 & 0\end{array}$ 
pREP retrain to crit. 40

pREP test

pREP retrain to crit. 40

pREP test

(1)

$\begin{array}{llllllllllll}10 & 10 & 10 & 9 & 0 & 0 & 1 & 0 & 0 & 0 & 0 & 0\end{array}$

pREP retrain to crit. 40

DMTS test

pREP retrain to crit. 40

DMTS test

$\begin{array}{llllllllllll}10 & 10 & 10 & 10 & 0 & 0 & 0 & 0 & 0 & 0 & 0 & 0\end{array}$

pREP retrain to crit. 40

pREP test

$\begin{array}{llllllllllll}10 & 10 & 10 & 10 & 0 & 0 & 0 & 0 & 0 & 0 & 0 & 0\end{array}$

$\begin{array}{llllllllllll}10 & 10 & 9 & 10 & 0 & 0 & 0 & 0 & 0 & 0 & 0 & 0\end{array}$

Subject 3

pREP train to crit. 240

pREP test

pREP retrain to crit. 40

pREP test

pREP retrain to crit. 40

pREP test

$\begin{array}{llllllllllll}10 & 10 & 10 & 10 & 0 & 0 & 0 & 0 & 0 & 0 & 0 & 0\end{array}$

pREP retrain to crit. 40

DMTS test

pREP retrain to crit. 40

pREP test

$\begin{array}{llllllllllll}9 & 10 & 7 & 10 & 0 & 0 & 0 & 0 & 3 & 0 & 0 & 0\end{array}$

$\begin{array}{llllllllllll}10 & 10 & 10 & 10 & 0 & 0 & 0 & 0 & 0 & 0 & 0 & 0\end{array}$

Subject 4

pREP train to crit. $\quad 40$

pREP test

pREP retrain to crit. 40

DMTS test

pREP retrain to crit. 40

pREP test

$\begin{array}{llllllllllll}10 & 10 & 10 & 10 & 0 & 0 & 0 & 0 & 0 & 0 & 0 & 0\end{array}$

Note. ${ }^{*} \mathrm{P}=$ Press, $\mathrm{NP}=$ No Press

$\begin{array}{cccccccccccc}8 & 10 & 10 & 10 & 10 & 10 & 0 & 0 & 0 & 0 & 0 & 0 \\ 10 & 10 & 10 & 10 & 10 & 10 & 0 & 0 & 0 & 0 & 0 & 0 \\ 10 & 10 & 10 & 10 & 10 & 10 & 0 & 0 & 0 & 0 & 0 & 0\end{array}$

\section{APPENDIX D}

Detailed Results for Each Exposure to MTS Tests and pREP Tests in Experiment 4

Experiment 4

Test tasks

Required response

SYMMETRY EQUIVALENCE NON-SYMMETRY NON-EQUIV.
A1 B2-A2 C1-B1 C2-B2 C1-A1 C2-A2 B1-A2 B2-A1 C1-B2 C2-B1 C1-A2 C2-A1

\section{Subject 1}

Set 1 stimuli

MTS train to crit. 120

MTS test

pREP train to crit. $\quad 40$

pREP test

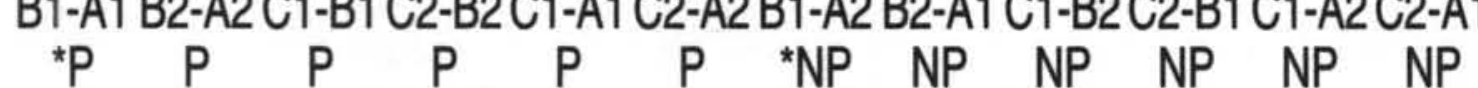

Set 2 stimuli

pREP train to crit. 40

pREP test

$\begin{array}{lllllllllllll}10 & 8 & 10 & 10 & 9 & 10 & 0 & 0 & 0 & 0 & 0 & 0\end{array}$

Subject 2

Set 1 stimuli

MTS train to crit. 120

MTS test

MTS retrain to crit. 40

MTS test

pREP train to crit. $\quad 40$

pREP test

$\begin{array}{llllllllllll}10 & 9 & 10 & 10 & 8 & 10 & 0 & 1 & 0 & 0 & 2 & 0\end{array}$

$\begin{array}{llllllllllll}10 & 10 & 10 & 10 & 10 & 10 & 0 & 1 & 0 & 0 & 0 & 0\end{array}$

$\begin{array}{llllllllllll}10 & 8 & 5 & 7 & 6 & 9 & 0 & 2 & 5 & 2 & 4 & 1\end{array}$

$\begin{array}{llllllllllll}10 & 9 & 10 & 10 & 10 & 10 & 0 & 1 & 0 & 0 & 0 & 0\end{array}$

$\begin{array}{llllllllllll}10 & 10 & 10 & 10 & 10 & 10 & 0 & 0 & 0 & 0 & 0 & 0\end{array}$ 
Set 2 stimuli

pREP train to crit. $\quad 80$

pREP test

pREP retrain to crit. 40

pREP test

$\begin{array}{llllllllllll}10 & 10 & 10 & 6 & 8 & 5 & 1 & 1 & 0 & 3 & 3 & 2\end{array}$

$\begin{array}{llllllllllll}10 & 9 & 10 & 10 & 10 & 8 & 0 & 1 & 0 & 0 & 0 & 1\end{array}$

Subject 3

Set 1 stimuli

MTS train to crit. $\quad 120$

MTS test

MTS retrain to crit. $\quad 80$

MTS test

MTS retrain to crit. $\quad 80$

MTS test

pREP train to crit. $\quad 80$

pREP test

pREP retrain to crit. $\quad 40$

pREP test

pREP retrain to crit. 40

pREP test

20

Set 2 stimuli

pREP train to crit. $\quad 80$

pREP test

$\begin{array}{llllllllllll}10 & 10 & 10 & 9 & 10 & 10 & 0 & 0 & 0 & 0 & 0 & 1\end{array}$

Subject 4

Set 1 stimuli

MTS train to crit. $\quad 40$

MTS test

MTS retrain to crit. $\quad 40$

MTS test

pREP train to crit. $\quad 40$

pREP test

$\begin{array}{llllllllllll}1 & 2 & 10 & 10 & 1 & 3 & 9 & 8 & 0 & 0 & 9 & 7\end{array}$

$\begin{array}{llllllllllll}0 & 9 & 10 & 10 & 1 & 1 & 10 & 1 & 0 & 0 & 9 & 9\end{array}$

$\begin{array}{llllllllllll}10 & 10 & 10 & 10 & 10 & 10 & 0 & 0 & 0 & 0 & 0 & 0\end{array}$

$\begin{array}{llllllllllll}8 & 10 & 9 & 10 & 0 & 1 & 0 & 0 & 0 & 0 & 1 & 0\end{array}$

$\begin{array}{llllllllllll}10 & 10 & 10 & 9 & 0 & 0 & 0 & 0 & 1 & 0 & 10 & 10\end{array}$

$\begin{array}{llllllllllll}10 & 10 & 10 & 10 & 10 & 8 & 0 & 0 & 0 & 0 & 1 & 0\end{array}$

Set 2 stimuli

pREP train to crit. $\quad 40$

pREP test

Note. ${ }^{*} \mathrm{P}=$ Press, $\mathrm{NP}=$ No Press

\section{APPENDIX E}

Detailed Results for Each Exposure to MTS Tests and pREP Tests in Experiment 5

Experiment 5

SYMMETRY EQUIVALENCE NON-SYMMETRY NON-EQUIV.

Test tasks

$B 1-A 1$ B2-A2 C1-B1 C2-B2C1-A1 C2-A2B1-A2 B2-A1 C1-B2 C2-B1 C1-A2 C2-A1

$\begin{array}{lllllllllllllllll}\text { Required response } & \text { No. trials } & { }^{*} P & P & P & P & P & P & & & \end{array}$

\section{Subject 1}

Set 1 stimuli

MTS train to crit. $\quad 80$

MTS test

$\begin{array}{llllllllllll}10 & 10 & 10 & 10 & 10 & 10 & 0 & 0 & 0 & 0 & 0 & 0\end{array}$

Set 2 stimuli

pREP train to crit.

80

pREP test

$\begin{array}{llllllllllll}10 & 10 & 10 & 10 & 10 & 10 & 1 & 0 & 0 & 1 & 0 & 0\end{array}$

Subject 2

Set 1 stimuli

MTS train to crit. $\quad 120$

MTS test

MTS retrain to crit. $\quad 40$

MTS test

MTS retrain to crit. $\quad 40$

MTS test

$\begin{array}{cccccccccccc}0 & 6 & 2 & 4 & 6 & 7 & 10 & 4 & 8 & 6 & 4 & 3 \\ 9 & 10 & 10 & 9 & 9 & 4 & 1 & 0 & 0 & 1 & 1 & 6 \\ 7 & 10 & 10 & 10 & 2 & 0 & 3 & 0 & 0 & 0 & 8 & 10\end{array}$


MTS retrain to crit. 40 MTS test $\begin{array}{llllllllllll}10 & 10 & 10 & 10 & 10 & 10 & 0 & 0 & 0 & 0 & 0 & 0\end{array}$

Set 2 stimuli

pREP train to crit. 200

pREP test

$\begin{array}{llllllllllll}8 & 10 & 10 & 10 & 10 & 10 & 0 & 0 & 1 & 0 & 0 & 0\end{array}$

Subject 3

Set 1 stimuli

MTS train to crit. $\quad 120$

MTS test

Set 2 stimuli

pREP train to crit. $\quad 280$

pREP test

pREP retrain to crit. 40

pREP test

Set 1 stimuli

MTS train to crit. $\quad 40$

MTS test

pREP train to crit. $\quad 40$

pREP test

$\begin{array}{llllllllllll}10 & 10 & 10 & 10 & 10 & 10 & 0 & 0 & 0 & 0 & 0 & 0\end{array}$

Set 2 stimuli

pREP train to crit. 120

pREP test

$\begin{array}{llllllllllll}8 & 10 & 9 & 10 & 0 & 0 & 2 & 0 & 0 & 0 & 10 & 0\end{array}$

$\begin{array}{llllllllllll}8 & 10 & 10 & 10 & 0 & 1 & 0 & 0 & 0 & 0 & 10 & 1\end{array}$

Subject 4

Set 1 stimuli

MTS train to crit. $\quad 120$

MTS test

$\begin{array}{llllllllllll}10 & 10 & 10 & 10 & 9 & 10 & 0 & 0 & 0 & 0 & 1 & 0\end{array}$

$\begin{array}{llllllllllll}10 & 10 & 10 & 10 & 10 & 10 & 0 & 0 & 0 & 0 & 0 & 0\end{array}$

Set 2 stimuli

pREP train to crit. 200

pREP test

pREP retrain to crit. 40

pREP test

$\begin{array}{llllllllllll}10 & 10 & 10 & 10 & 10 & 10 & 0 & 0 & 0 & 0 & 0 & 0\end{array}$

Set 1 stimuli

MTS train to crit. $\quad 40$

MTS test

pREP train to crit. $\quad 40$

pREP test

40

$\begin{array}{llllllllllll}10 & 10 & 10 & 9 & 9 & 10 & 0 & 0 & 0 & 0 & 1 & 0\end{array}$

$\begin{array}{llllllllllll}10 & 10 & 10 & 10 & 10 & 10 & 1 & 1 & 0 & 1 & 10 & 10\end{array}$

$\begin{array}{llllllllllll}10 & 10 & 10 & 10 & 10 & 10 & 0 & 0 & 0 & 1 & 10 & 9\end{array}$

Set 2 stimuli

pREP train to crit. $\quad 80$

pREP test

Note. ${ }^{*} \mathrm{P}=$ Press, $\mathrm{NP}=$ No Press 